\title{
Detection, Quantitative Collection and Semiquantitative Determination of Bismuth(III) and Zinc(II) in Aqueous Media Using Polyurethane Foam Treated with Dithizone
}

\author{
A.-G. Hamza*, A. B. Farag**, T. A. Amireh*, Z. E. El-Basyouni* and F. M. Al-Nowaiser* \\ *Department of Chemistry, Faculty of Science, King Abdulaziz University, Jeddah 21413, Saudi Arabia \\ ** Department of Chemistry, Faculty of Science, University of Qatar, Doha, State of Qatar
}

\begin{abstract}
The analytical utility of dithizone foam for the detection, quantitative collection and semiquantitative determination of traces of bismuth and zinc in aqueous solutions has been examined. The effect of $\mathrm{pH}$ on the sensitivity and selectivity of the proposed foam tests has been investigated. The detection limits of bismuth and zinc by the foam batch method are 0.02 and $0.003 \mathrm{ppm}$, respectively. The effect of diverse ions on the detection of bismuth and zinc has been critically investigated. A quantitative collection of bismuth and zinc from extremely dilute aqueous acidic solutions by the proposed foam column method has been successfully carried out.
\end{abstract}

Keywords Polyurethane foam test, dithizone, extraction, bismuth, zinc, qualitative inorganic analysis, semiquantitative inorganic analysis

Diphenylthiocarbazone (dithizone) is an extremely sensitive reagent that can be used for the extraction and determination of microgram quantities of many metal ions. ${ }^{1-3}$ Metal dithizonate complexes are easily extracted with various organic solvents. It is known that dithizone is not a selective reagent in neutral and alkaline media. However, its selectivity is generally increased at lower $\mathrm{pH}$ values and by adding a complex forming agent or masking agent to the aqueous solution. ${ }^{4}$

Polyurethane foams loaded with dithizone have been employed for the quantitative collection and preconcentration of mercury ${ }^{5}$, silver ${ }^{6}$ and other metal ions from their dilute aqueous solutions. Foams loaded with other organic reagents (Chromofoams) have been suggested ${ }^{7-13}$ for the sensitive detection and semiquantitative determination of several metals.

No work has been done on the application of dithizone loaded foam for the detection, collection and preconcentration of bismuth(III) and zinc(II) in aqueous media. The only work reported ${ }^{14}$ regarding the detection of zinc with dithizone foam was carried out in a neutral medium in which the reagent foam is not selective. Accordingly, this paper describes the use of dithizone foam for the selective detection, quantitative collection and semiquantitative determination of traces of bismuth and zinc in aqueous acidic solutions.

\section{Experimental}

\section{Reagents and materials}

All reagents were of analytical-grade unless otherwise specified. An open-cell polyether type polyurethane foam (bulk density $30 \mathrm{~kg} \mathrm{~m}^{-3}$ ) was supplied by $\mathrm{K}$. G. Greiner, Schaumstoffwerk-Kremünster, Austria. The foam material (cubes of $c a .5 \mathrm{~mm}$ edge) was washed and dried as previously described. ${ }^{14}$ Stock solutions containing $1 \mathrm{mg} \mathrm{ml}^{-1}$ of bismuth and zinc were prepared by dissolving the appropriate amounts of bismuth(III) nitrate and zinc(II) sulfate in deionized water acidified with a few drops of $1 \mathrm{M}$ nitric acid solution and standardized by EDTA titration. Series of standard bismuth and zinc solutions were prepared by dilution with water acidified with a few drops of $1 \mathrm{M}$ nitric acid solution.

The dithizone solution was prepared by dissolving $0.05 \mathrm{~g}$ of dithizone in $100 \mathrm{ml}$ of chloroform. The reagent foam was prepared by mixing the dried foam cubes and the dithizone solution ( $5 \mathrm{ml} \mathrm{g}^{-1}$ dry foam) with efficient stirring for $5 \mathrm{~min}$. The dithizone-loaded foam material was then squeezed between two watch glasses to remove any excess of dithizone solution.

A foam column was prepared by packing $1 \mathrm{~g}$ of the reagent foam cubes in a glass column $(1 \mathrm{~cm}$ diameter and $15 \mathrm{~cm}$ long) filled with sufficient water to immerse the foam material. Air bubbles in the foam bed were removed by compressing the cubes several times with a glass rod.

In batch (static) experiments, one dithizone-loaded foam cubes is mixed and shaken with $1-3 \mathrm{ml}$ of the test solution for 2-3 min. A color change of the foam from green to orange-brown or pink, in the presence of bismuth and zinc, respectively, was observed. For a semiquantitative determination of bismuth and zinc, 
standard color scales were prepared with a series of standard solutions of different concentrations of each metal ion. The concentration of the unknown sample was determined by a comparison.

In the column (dynamic) experiment 10, 100 and $250 \mathrm{ml}$ of the test solution were allowed to percolate through the foam column at flow rates of $0.5-1.0$ and 3-5 $\mathrm{ml} \mathrm{min}^{-1}$ with bismuth and zinc solutions, respectively.

\section{Instrumentation}

Atomic absorption measurements were carried out using a Perkin Elmer graphite furnace atomic absorption spectrophotometer, Model AA 5000.

\section{Results and Discussion}

\section{Determination of bismuth with dithizone foam}

Dithizone forms an insoluble orange-brown color complex with bismuth(III) $\left(\mathrm{Bi}(\mathrm{HDz})_{3}\right)$ that is readily extracted by organic solvents without any color change. ${ }^{4}$ This reaction was tried with foam loaded with dithizone to detect bismuth in acidic aqueous solutions $(\mathrm{pH} \approx 1.2)$. At this $\mathrm{pH}$, the complexation reaction is quite selective for bismuth. Since the primary bismuth

Table 1 Detection of bismuth(III) with dithizone foam in the presence of some interfering ions

\begin{tabular}{|c|c|c|c|}
\hline $\begin{array}{c}\text { Foreign } \\
\text { ion }\end{array}$ & $\begin{array}{l}\text { Compound } \\
\text { added }\end{array}$ & $\begin{array}{c}\text { Tolerance } \\
\text { limit }\end{array}$ & Note \\
\hline $\mathrm{Sr}^{2+}$ & $\mathrm{SrCl}_{2} \cdot 6 \mathrm{H}_{2} \mathrm{O}$ & $1: 1 \times 10^{3}$ & \\
\hline $\mathrm{Ni}^{2+}$ & $\mathrm{NiSO}_{4} \cdot 6 \mathrm{H}_{2} \mathrm{O}$ & $1: 1 \times 10^{3}$ & \\
\hline $\mathrm{Zr}^{4+}$ & $\mathrm{ZrOCl}_{2} \cdot 8 \mathrm{H}_{2} \mathrm{O}$ & $1: 1 \times 10^{3}$ & \\
\hline $\mathrm{Au}^{3+}$ & $\mathrm{AuCl}_{3}$ & $1: 1 \times 10^{3}$ & \\
\hline $\mathrm{Hg}^{\mathbf{2}^{+}}$ & $\mathrm{Hg}\left(\mathrm{NO}_{3}\right)_{2} \cdot \mathrm{H}_{2} \mathrm{O}$ & $1: 1 \times 10^{3}$ & $\begin{array}{l}\text { Add } 0.5 \mathrm{ml} \text { of a } \\
\text { saturated ascorbic } \\
\text { acid solution. }\end{array}$ \\
\hline $\mathrm{Cd}^{2+}$ & $\mathrm{Cd}\left(\mathrm{NO}_{3}\right)_{2} \cdot 4 \mathrm{H}_{2} \mathrm{O}$ & $1: 1 \times 10^{4}$ & $\begin{array}{l}\text { Add a few crystals } \\
\text { of } \mathrm{Na}_{2} \mathrm{SO}_{3} \text {. }\end{array}$ \\
\hline $\mathrm{Cu}^{2+}$ & $\mathrm{CuSO}_{4} \cdot 5 \mathrm{H}_{2} \mathrm{O}$ & $1: 1 \times 10^{4}$ & $\begin{array}{l}\text { Adjust the } \mathrm{pH} \text { of } \\
\text { the aqueous soln. } \\
\text { to } \simeq 0.8 \text {. }\end{array}$ \\
\hline $\mathrm{Fe}^{3+}$ & $\mathrm{FeCl}_{3} \cdot 6 \mathrm{H}_{2} \mathrm{O}$ & $1: 1 \times 10^{4}$ & $\begin{array}{l}\text { Add a few crystals } \\
\text { of } \mathrm{NaF} \text {. }\end{array}$ \\
\hline $\mathrm{Ag}^{+}$ & $\mathrm{AgNO}_{3}$ & $1: 1 \times 10^{4}$ & $\begin{array}{l}\text { Add a few crystals } \\
\text { of KSCN or } \\
\text { thiourea. }\end{array}$ \\
\hline $\mathrm{S}_{2} \mathrm{O}_{8}{ }^{2-}$ & $\mathrm{K}_{2} \mathrm{~S}_{2} \mathrm{O}_{8}$ & $1: 1 \times 10^{3}$ & \\
\hline $\mathrm{VO}_{3}^{-}$ & $\mathrm{NH}_{4} \mathrm{VO}_{3}$ & $1: 1 \times 10^{3}$ & \\
\hline $\mathrm{WO}_{4}^{-}$ & $\mathrm{Na}_{2} \mathrm{WO}_{4} \cdot 2 \mathrm{H}_{2} \mathrm{O}$ & $1: 1 \times 10^{3}$ & \\
\hline Oxalate & sodium oxalate & $1: 1 \times 10^{3}$ & $\begin{array}{l}\text { Add bromine water } \\
\text { and boil. }\end{array}$ \\
\hline $\mathrm{MnO}_{4}^{-}$ & $\mathrm{KMnO}_{4}$ & $1: 1 \times 10^{4}$ & $\begin{array}{l}\text { Add a few crystals } \\
\text { of } \mathrm{Na}_{2} \mathrm{~S}_{2} \mathrm{O}_{3} \text {. }\end{array}$ \\
\hline $\mathrm{S}_{2} \mathrm{O}_{3}{ }^{2-}$ & $\mathrm{Na}_{2} \mathrm{~S}_{2} \mathrm{O}_{3} \cdot 5 \mathrm{H}_{2} \mathrm{O}$ & $1: 1 \times 10^{4}$ & $\begin{array}{l}\text { Add bromine water } \\
\text { and boil. }\end{array}$ \\
\hline $\mathbf{I}^{-}$ & $\mathbf{K I}$ & $1: 1 \times 10^{4}$ & $\begin{array}{l}\text { Add bromine water } \\
\text { and boil. }\end{array}$ \\
\hline
\end{tabular}

dithizonate complex collected on the relatively high available surface area of the foam cube is quite stable and the characteristic color can easily be observed on the foam, it was possible to detect bismuth at a concentration as low as $0.02 \mathrm{ppm}\left(\mu \mathrm{g} \mathrm{ml}^{-1}\right)$ using the foam batch extraction mode.

To examine the selectivity of this dithizone foam test, the detection of bismuth in the presence of diverse types of ions was studied using a straight-forward foam batch method. It was found possible to detect $1 \mu \mathrm{g}$ of bismuth in the presence of up to $10 \mathrm{mg}$ of $\mathrm{Ca}^{2+}, \mathrm{Ba}^{2+}$, $\mathrm{Mg}^{2+}, \mathrm{Mn}^{2+}, \mathrm{Pb}^{2+}, \mathrm{Co}^{2+}, \mathrm{Tl}^{+}, \mathrm{Zn}^{2+}, \mathrm{Cl}^{-}, \mathrm{Br}^{-}, \mathrm{F}^{-}, \mathrm{SO}_{3}{ }^{2-}$, $\mathrm{BrO}_{3}{ }^{-}, \mathrm{ClO}_{3}{ }^{-}, \mathrm{ClO}_{4}^{-}, \mathrm{SeO}_{3}{ }^{2-}, \mathrm{S}_{2} \mathrm{O}_{5}{ }^{2-}$, acetate, thiourea, ascorbate, tartrate, citrate and phosphate. In the presence of some other ions, a simple modification of the sample solution afforded unambiguous and sensitive detection of bismuth (Table 1).

A semiquantitative determination of bismuth was possible by a comparison of the color of the foam cube with standards prepared with $0.02,0.1,0.5,1.0$ and $20 \mathrm{ppm}$ bismuth solutions under the same experimental conditions. Bismuth at lower concentrations $(\leqq 0.01$ ppm) can be detected by passing $10 \mathrm{ml}$ or more of bismuth solution through the reagent foam column at a rate of $0.5-1.0 \mathrm{ml} \mathrm{min}^{-1}$. The length of the colored zone is proportional to the bismuth concentration, which could be estimated using standards covering the range of 0.01 to $5 \mu \mathrm{g} \mathrm{ml}^{-1}$. Figure 1 shows, e.g., the relationship between the bismuth concentration in $10 \mathrm{ml}$ aqueous solution and the length of the colored zone on the foam column. Similar linear relationships were also obtained with 100 and $250 \mathrm{ml}$ bismuth solutions.

It is worth to mention that, the length of the colored zone is not affected by dilution, i.e., $1 \mu \mathrm{g}$ of bismuth in 10,100 or $250 \mathrm{ml}$ of aqueous solution $(\mathrm{pH} \approx 1.2)$ gave more or less the same length of the colored zone on the dithizone foam columns. That is, foam visual colorimetry could be successfully employed for a semiquantitative determination of bismuth in an extremely dilute aqueous solution.

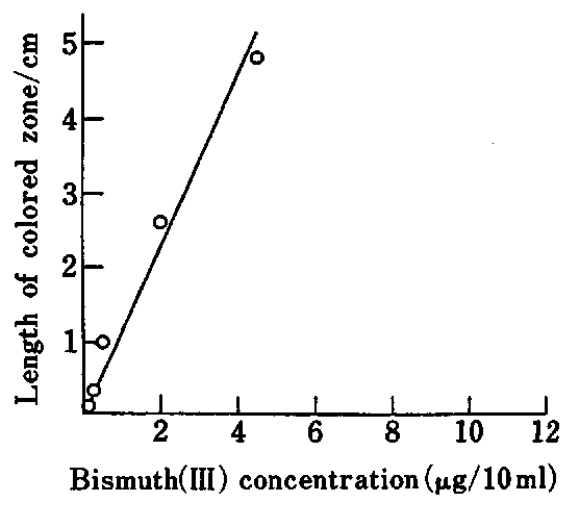

Fig. 1 Relationship between the bismuth concentration and the length of the colored zone. 
An attempt was made for a quantitative collection of bismuth(III) on columns packed with dithizone foam. The foam bed was $9.0 \mathrm{~cm}$ in length, and bismuth solutions $(\mathrm{pH} \simeq 1.2)$ containing $10 \mu \mathrm{g}$ of bismuth in 10,100 or $250 \mathrm{ml}$ were allowed to pass through the foam columns at a flow rate of $0.5-1.0 \mathrm{ml} \mathrm{min}$.

Bismuth was determined in the effluent solutions by an atomic absorption spectrophotometric method using a hydride system. The obtained results show that bismuth could be quantitatively collected from these dilute aqueous solutions onto the foam column, since no bismuth could be detected in the effluent solutions.

\section{Determination of zinc with dithizone foam}

Dithizone forms a pink colored primary complex with zinc in neutral and slightly alkaline media. ${ }^{4}$ This reagent has been employed for the preconcentration and quantitative determination of zinc in liquid-liquid extraction systems. Carbon tetrachloride and chloroform were employed as solvents with aqueous zinc solutions at pHs 6-9.5 and 7-10, respectively. Hydrophobic gel impregnated with dithizone has been used for the collection of zinc in aqueous solution employing column extraction system at pHs 4-7. Polyurethane foam loaded with dithizone has been suggested ${ }^{14}$ for the detection and semiquantitative determination of zinc in aqueous solution at pH 6.2. Unfortunately, however, this method is not selective for zinc since at this relatively high $\mathrm{pH}$ many other heavy metals react with dithizone while producing different colored complexes. ${ }^{4}$

In batch extraction experiments the effect of the $\mathrm{pH}$ of the aqueous solution on the extraction of zinc with dithizone foam has been critically evaluated. During this study a few drops of a saturated sodium sulfite solution was added in a trial to prevent the oxidation of the reagent to diphenylthiocarbadiazone $(\mathrm{S}=\mathrm{C}(\mathrm{N}=$ $\left.\mathrm{NC}_{6} \mathrm{H}_{5}\right)_{2}$ ) which does not react with zinc.

In the absence of sulfite ion the suitable $\mathrm{pH}$ for the extraction of zinc with dithizone foam was found to be in the range 4.5 to 6.5 . Surprisingly, however, in the presence of sulfite ion in aqueous solution, zinc was extracted and the pink colored complex of zinc was clearly observed on the reagent foam material at lower pHs (nearly 1.8). Thus, solutions having pHs ranging between 1.8 and 6.5 are quite suitable for the extraction of zinc with the proposed dithizone foam in the presence of sulfite ion. Moreover, the color of the zinc complex seems to be more intense in the presence of sulfite ions which allow the detection of as low as $0.003 \mathrm{ppm}$ of zinc. Figure 2 shows the effect of the $\mathrm{pH}$ of an aqueous solution in the presence of sodium sulfite on the collection of zinc with dithizone foam in batch extraction experiments. Zinc remaining in the aqueous phase was measured by an atomic absorption spectrophotometric method and the percentage of zinc retained on the reagent foam was calculated in terms of the difference.

Most probably, sulfite ion participates in a mixed coordination sphere, i.e., a triple complex ${ }^{15}$, may be

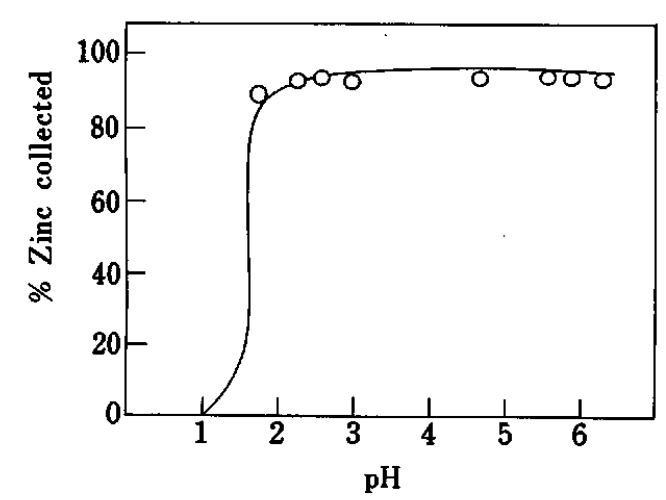

Fig. 2 Effect of the $\mathrm{pH}$ of the aqueous solution on the extraction of zinc with dithizone foam. Concentration of $\mathrm{Zn}^{2+}: 1 \mu \mathrm{g} / 3 \mathrm{ml}$ aqueous solution containing $1 \%$ sodium sulfite; shaking time: $3 \mathrm{~min}$ with one reagent foam cube.

formed, since the pink color of the zinc dithizonate complex is more clearly observed and is also more stable.

At this stage, this finding was applied to the detection and semiquantitative determination of zinc using dithizone foam cubes at pH 1.8. The proposed method was found to be quite selective. At this $\mathrm{pH}$ value the effect of different ions (previously mentioned during testing of the selectivity of dithizone foam for the extraction of bismuth) were found to have no effect on the detection of zinc with dithizone foam. Interference due to the presence of the ions listed in Table 1 are eliminated in a similar way as in the case of bismuth. The only interference was observed in the presence of mercury, silver, copper or bismuth together with zinc in an aqueous media. However, this interference could be successfully eliminated by the addition of a few crystals of sodium thiosulfate, which prevent the reaction of these metal ions with dithizone foam.

A semiquantitative determination of zinc in a foam batch extraction system was also possible using a standard color scale covering the concentration range of 0.003 to $5 \mathrm{ppm}$.

A further important advantage of the proposed reagent foam is the possibility of using it for a semiquantitative determination and a quantitative collection of zinc from an extremely dilute acidic aqueous solution employing a foam column extraction technique in a way similar to that described regarding bismuth. A flow rate of 3-5 $\mathrm{ml} \mathrm{min}^{-1}$ was found to be suitable for this purpose.

\section{References}

1. F. F. Dyer and G. K. Schweitzer, Anal. Chim. Acta, 23, 1 (1960).

2. A. K. De, S. M. Khopkar and R. A. Chalmers, "Solvent Extraction of Metals", Van Nostrand Reinhold, London, 1970. 
3. G. Iwantscheff, "Das Dithizone und seine Anwendung in der Mikro- und Spurenanalyse", 2nd ed., Verlag Chemie, Weinhein, 1972.

4. Z. Marczenko, "Separation and Spectrophotometric Determination of Elements", Ellis Horwood, Chichester, 1986.

5. T. Braun and A. B. Farag, Anal. Chim. Acta, 71, 133 (1974).

6. T. Braun and A. B. Farag, Anal. Chim. Acta, 69, 85 (1974).

7. T. Braun, J. D. Navartil and A. B. Farag, "Polyurethane Foam Sorbents in Separation Science", CRC Press, Boca Raton, 1985.

8. A.-G. Hamza, A. B. Farag and A. Al-Herthani, Microchem. $J ., 32,13$ (1985).

9. A. B. Farag, A. El-Waseef and M. H. Abdel-Rahman, Acta Chim. Hung., 122, 273 (1986).
10. A. B. Farag, M. A. Morsi and S. A. Ibrahim, Indian J. Chem., 25A, 882 (1986).

11. A. -G. Hamza, T. A. Amireh, A. B. Farag, Z. E. ElBasyouni and F.M. Al-Nowaiser, Proceedings of 2nd National Meeting of Chemistry, Saudi Arabia, 1987, p. 35.

12. A. B. Farag, A. M. El-Wakil, M. E. M. Hassouna and M. H. Abdel-Rahman, Anal. Sci., 3, 541 (1987).

13. A. B. Farag, A. M. A. Helmy, M. S. El-Shahawi and S. Farrag, Analusis, 17, 478 (1989).

14. T. Braun and A. B. Farag, Anal. Chim. Acta, 73, 301 (1974).

15. K. S. Math and H. Freiser, Anal. Chem., 41, 1682 (1969).

(Received May 10, 1990)

(Accepted June 21, 1990) 